\title{
Methylnaltrexone Bromide
}

National Cancer Institute

\section{Source}

National Cancer Institute. Methylnaltrexone Bromide. NCI Thesaurus. Code C80569.

The bromide salt form of methylnaltrexone, a methyl derivative of noroxymorphone with selective, peripherally-acting mu-opioid receptor antagonistic activity. Methylnaltrexone displaces opioids from peripheral opioid receptors in the gastrointestinal tract, the bladder, and the skin, thereby reversing the opioid-related peripheral side-effects, such as constipation, urinary retention, and pruritis, respectively. Unlike naltrexone and due to the presence of a positively charged nitrogen atom in methylnaltrexone, this agent does not cross the blood-brain barrier and does not affect the centrally-mediated analgesic effect of opioids. 